\title{
Sporadic secreting paraganglioma
}

INSERM

\section{Source}

INSERM. (1999). Orphanet: an online rare disease and orphan drug data base. Sporadic secreting paraganglioma. ORPHA:276627

A rare tumor of endocrine glands characterized by a sporadic, extra-adrenal, catecholamine-secreting, chromaffin cell tumor located anywhere along the sympathetic ganglia (most frequently in the abdomen and pelvis), typically manifesting with episodic hypertension, cephalea, diaphoresis, heart palpitations, and, occasionally, hyperglycemia, anxiety/panic attacks, fever, weight loss, myocardial infarction, osteolytic bone metastases, and Raynaud's phenomenon. 